\title{
Tungsten Resource-Saving: Cobalt Cermets Wastes Recycling and Concentrates Extraction
}

\author{
Viktor Malyshev ${ }^{1}$, Dmytro Shakhnin ${ }^{1}$, Angelina $\mathrm{Gab}^{2}$, Nataliya Uskova ${ }^{1}$, Oleksandr Gudymenko ${ }^{1}$, Volodymyr \\ Glushakov $^{1}$ and Nina Kushchevska ${ }^{3}$ \\ 1. Department of Physical Chemistry of Ionic Liquids, V.I. Vernadsky Institute of General and Inorganic Chemistry, National \\ Academy of Sciences of Ukraine, Kyiv 03142, Ukraine \\ 2. Faculty of Chemistry \& Technology, National Technical University of Ukraine "Kyiv Polytechnical Institute", Kyiv 03056, \\ Ukraine \\ 3. Faculty of Engineering \& Technology, University “Ukraine”, Kyiv 03115, Ukraine
}

\begin{abstract}
Potentials range is determined in which the cobalt-tungsten alloy phase selectively dissolved in solutions of phosphoric acid to form soluble compounds of these metals, while the tungsten carbide phase remains in the precipitate. It shows that tungsten ores and concentrates are decomposed at $1,050{ }^{\circ} \mathrm{C}-1,100{ }^{\circ} \mathrm{C}$ in sodium chloride-sodium metasilicate melts to form two immiscible phases, namely, halide-tungstate, containing $96 \%$ to $99 \%$ of tungsten, and silicate, containing $90 \%$ of the rest ore components.
\end{abstract}

Key words: Tungsten, carbide, cobalt, halide-metasilicate melts, phosophric acid, electrochemical dissolution, recycling, extraction.

\section{Introduction}

Tungsten secondary raw materials are represented mainly by wastes of tungsten metal and tungsten containing hard alloys. Recycling technologies of various kinds of tungsten wastes are summarized [1, 2].

Existing methods of extracting the components of hard alloys differ from each other not only by the treatment mode but also by the used chemical reactants nature. Essential disadvantage of methods of hard alloys components dissolution with the use of various acids and their mixtures consists in the toxicity of the reagents were used. This disadvantage is partially eliminated by treating wasted diamond and hard-alloy tools with anodic dissolution in hydroxide-chloride melts [3]. In this case, the tungsten and carbon transfer into the melt in the form of tungstate and carbonate, respectively. The

Corresponding author: Viktor Malyshev, Ph.D., research fields: electrochemistry, molten salts, low-temperature ionic liquids, nanostructured materials, protective coatings deposition and hard alloys wastes recycling. impregnating materials for the hard-alloy matrix accumulate at the cathode in the form of finely dispersed metal powders. The end product of the proposed method is tungsten oxide $\mathrm{WO}_{3}$, which requires further treatment to be returned into the process of manufacturing hard-alloy tools.

Relatively long time ago, a simple and effective tungsten utilization technology from used drill bits wastes was developed including oxidative melting in arc furnace and use of tungsten containing slag for high speed cutting steel smelting [4].

Zinc method is based on dissolving the cobalt component of hard-alloys wastes in the molten zinc with subsequent melt distillation [5]. If regenerated hard-alloy contains an appreciable amount of zinc, the following technique may be used [6]. Liquid extraction of cobalt by zinc is replaced by diffusion introduction of gaseous zinc into hard alloys of VK type [7]. It is still considered possible to use oxidizing roasting as a first processing stage, which was first proposed in the patent of the Russian federation [8]. To recycle the scrap of hard-alloy roller bits, oxidative 
roasting of raw materials at $950{ }^{\circ} \mathrm{C}-1,050{ }^{\circ} \mathrm{C}$ is proposed with the subsequent treatment by the $\mathrm{NaOH}-\mathrm{NaNO}_{3}-\mathrm{NaCl}$ melt at $450{ }^{\circ} \mathrm{C}-550{ }^{\circ} \mathrm{C}$ [9]. Another technique [10] involves, after the oxidative roasting, the leaching of cobalt by $30 \%-40 \%$ solution of $\mathrm{H}_{2} \mathrm{SO}_{4}$, tungsten cake separation, and evaporation of the solution precipitate the cobalt sulfate.

The method claimed in the patent of Russian Federation [11] can be used for the processing of scrap as well as powder and dust like wastes of tungsten carbide-cobalt hard-alloys. This process begins with treating the raw materials by solution of oxidant (sodium hypochlorite) in an alkaline medium. Then, the separation of tungsten (as solid tungstic acid precipitate) and cobalt (in the solution) is done by the introduction of the mixture resulted from oxidation into the hot hydrochloric acid solution with the subsequent filtration.

Wastes of hard alloys based on tungsten carbide with cobalt binder, as well as wastes of metal tungsten, can be processed by fluorination with elemental fluorine. It was found that, within the temperature range $298 \mathrm{~K}-1,400 \mathrm{~K}$, besides the formation of $\mathrm{WF}_{6}$, there is high thermodynamic probability of formation of $\mathrm{CF}_{4}, \mathrm{C}_{2} \mathrm{~F}_{6}, \mathrm{CoF}_{3}$ and atomic fluorine [12].

Two new technologies for processing of hard-alloys wastes were proposed by the Austrian scientists. An environmentally friendly technology of wastes recovery was described for hard-alloys containing $\mathrm{WC}$, TiC, TaC, NbC, chromium, vanadium, and cobalt binder $(8 \%-15 \% \mathrm{Co})$ [13]. The process is based on selective leaching of crushed down to about $10 \mathrm{~mm}$ wastes by $\mathrm{CH}_{3} \mathrm{COOH}$ solutions.

A multistage technology is proposed designed for processing grinding swarf of the following composition (\%): WC, 78.67; Co, 10.13; SiC, 1.68 and other carbides, 6.8 [14]. The following publications should be mentioned concerning recycling of the tungsten carbide - cobalt hard-alloys by oxidation and wet milling processes, by hydrometallurgical processes, and by microbial destruction of tungsten and cobalt containing wastes [15-19].

In this paper, the separation of cobalt and tungsten carbide by anodic dissolution in phosphoric acid solutions were studied. Electrode potentials, cathode processes with electrochemical evolution of gas, and oxidation processes with participation of tungsten and its carbide were studied mostly in hydrochloric and sulfuric acid solutions [20]. The electrochemical hydrogen evolution on tungsten carbide was studied by Baibatyrov et al. [21]. It showed that the hydrogen evolution on WC is limited by the recombination of the adsorbed hydrogen atoms. The shape of the anode polarization curves in sulfuric acid solutions corresponds to the transition of the active dissolution of the metal to its passive state [20].

Tungsten compounds are usually extracted from ores and concentrates by dissolution in different acids, the environmental danger and technological ineffectiveness of which are obvious. In this paper, the method of high-temperature selective extraction of tungsten from its concentrates was studied, and the most effective process conditions (temperature, melt composition, extraction duration) were determined.

\section{Experimental}

The anodic dissolution of the WC-Co alloy, metallic cobalt, and tungsten carbide WC electrodes was studied using a three-electrode system. The working electrolyte was $1.25 \mathrm{M}$ solution of phosphoric acid $\mathrm{H}_{3} \mathrm{PO}_{4}$. Small-bar electrodes were made of the WC-Co (6\%) hard-alloy by the Svetlovodsk Factory of Hard Alloys and Refractory Metals using the regular process of powder metallurgy. The tungsten carbide electrodes were manufactured by the pressure sintering of tungsten carbide powders at $2,200{ }^{\circ} \mathrm{C}$ and $9.8 \mathrm{GPa}$ in the laboratory of the Institute of Materials Science Problems of the National Academy of Sciences of Ukraine. The cobalt electrodes were plates (surface area 1-2 $\mathrm{cm}^{2}$ ) made of an ultrapure metallic foil. Before measurements, the 
working electrodes were carefully ground and polished using the procedures recommended for this type of materials [22]. The polished surface was treated with alcohol and distillated water immediately before the measurements. Platinum plate of surface area $1.0-1.5 \mathrm{~cm}^{2}$ was used as an auxiliary electrode. The potentials of the electrodes were measured relative to a saturated calomel electrode located outside the cell and connected to it via a salt bridge. All measurements were conducted in a nitrogen atmosphere at a temperature of $18{ }^{\circ} \mathrm{C}$. Steady-state potentiostatic curves were obtained using a PI-50-1 potentiostat by recording the established value of the current. The same equipment and a PDP-4 recorder were used to measure the time dependence of the electric current. Metallographic studies were performed using a Neophot-21 electronic microscope. The phase composition of solid samples and gases were identified using a DRON-4.0 X-ray diffractometer and a Selmikhrom-1 chromatograph, respectively. Argon or helium was used as a carrier gas. The measured data were processed using an IBM-486 personal computer. Concentration curves for the distribution of cobalt and tungsten over microsections were obtained using an "MS-46 Cameca" X-ray microanalyzer. Partial currents during the dissolution of the metals were determined by comparing the recorded current with the values determined from the results of analyzing the solutions obtained.

The tungsten concentrates used for the study had the following chemical composition ( $\mathrm{wt} \%$ ): $\mathrm{WO}_{3}$, 65-71; $\mathrm{FeO}, 8.5-9.2 ; \mathrm{MnO}, 13.5-20.5 ; \mathrm{Sb}_{2} \mathrm{O}_{5}, 0.5-1.5$; $\mathrm{SiO}_{2}, 0.5-1.2$ and $\mathrm{TiO}_{2}, 0.4-1.1$.

Chemically pure sodium chloride and sodium metasilicate were used for high-temperature selective extraction. The extraction was accomplished in silicon carbide crucibles having an inner diameter of $50 \mathrm{~mm}$ and a height of $150 \mathrm{~mm}$. The charge for hightemperature selective extraction had the following composition (wt\%): $\mathrm{NaCl}, 45.0 ; \mathrm{Na}_{2} \mathrm{SiO}_{3}, 20.0$ and wolframite, 35.0. The operating temperature of the process was $1,000{ }^{\circ} \mathrm{C}-1,100{ }^{\circ} \mathrm{C}$, and its duration was up to $2 \mathrm{~h}$. The liquid halide-tungstate phase was decanted into a separate crucible for further treatment. More viscous silicate phase was drenched with water. The small amount of tungstate contained in the silicate phase was dissolved in water and separated from the extracting solution in the form of calcium tungstate.

\section{Results and Discussion}

\subsection{Recycling of Waste Tungsten Carbide-Cobalt Hard Alloys in Phosphoric Acid Solutions}

Fig. 1 illustrates the typical steady-state potentiostatic polarization curves for the anodic dissolution of the WC-Co (6\%) hard-alloy, cobalt, and tungsten carbide and the reduction of hydrogen ions on the tungsten carbide electrode. The polarization curves are reproduced in the cycling of the potential almost without any hysteresis. The stirring does not affect the behavior of the curves. The value of the steady-state potential of the WC-Co $(6 \%)$ electrode is $-(0.32-0.34) \mathrm{V}$ and is located between the values of the potentials of its components: $-(0.55-0.57) \mathrm{V}$ for cobalt and -(0.09-0.11) V for tungsten carbide. The polarization curves for the WC-Co (6\%) electrode (curve 1) show three clearly cut zones. In the first zone, $-0.30 \mathrm{~V}$ to $-0.05 \mathrm{~V}$, the value of the logarithm of the electric current density increases linearly with increasing potential. At a potential value of $-0.02 \mathrm{~V}$, the current density sharply decreases and remains almost constant until the potential increases to $0.70 \mathrm{~V}$ (second zone). As the potential increases further, the electric current density again exponentially increases (third zone).

The anodic dissolution of the WC-Co (6\%) bars was accomplished under potentiostatic conditions at potential values of $-0.25 \mathrm{~V}$ to $-0.05 \mathrm{~V}$, which correspond to the first section of the potentiostatic curve. In this case, the electric current density slowly decreases with time (usually, during $10 \mathrm{~h}$ to $12 \mathrm{~h}$ ) and then remains almost constant (Fig. 2). 


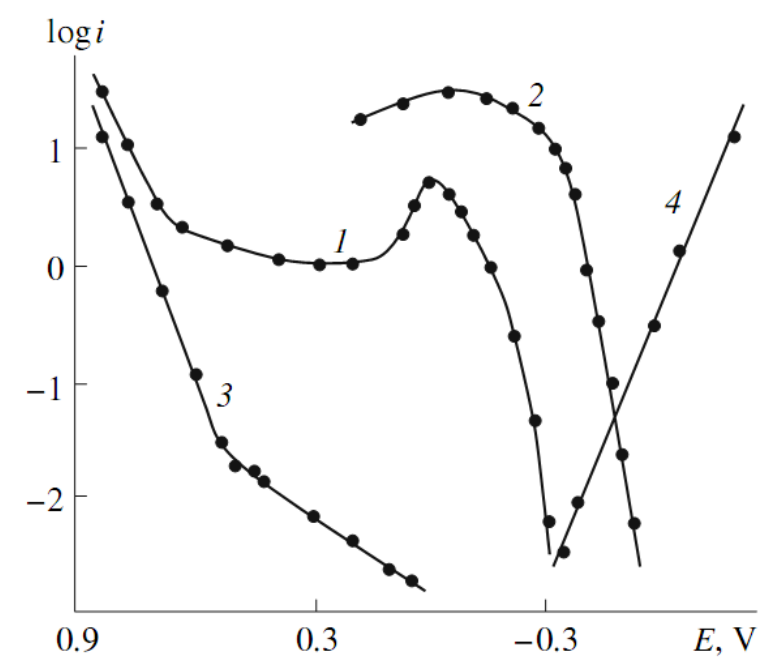

Fig. 1 Steady-state potentiostatic polarization curves for the anodic dissolution of (1) the WC-Co (6\%) hard alloy, (2) cobalt, (3) tungsten carbide and (4) the reduction of hydrogen ions on the tungsten carbide electrode in the 1.25 $\mathrm{M} \mathrm{H}_{3} \mathrm{PO}_{4}$ solution at a temperature of $18^{\circ} \mathrm{C}$.

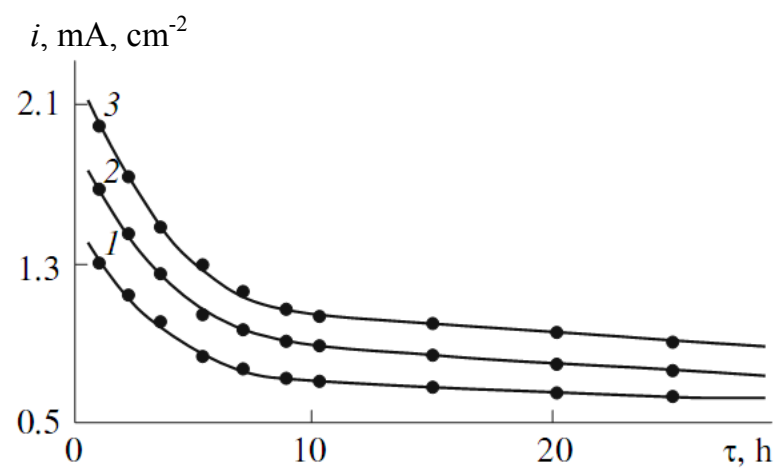

Fig. 2 Time dependence of the rate of dissolution of the CO-W phase from the WC-Co $(6 \%)$ hard alloy at electrode potentials of (1) $-0.15 \mathrm{~V}$, (2) $-0.20 \mathrm{~V}$, (3) $-0.25 \mathrm{~V}$ and a temperature of $18^{\circ} \mathrm{C}$.

Two zones on the surface of the cross-sectional microsection of the WC-Co (6\%) bar treated by anodic dissolution can be visually observed (Fig. 3). The observed boundary separates the base, which was not dissolved, from the partially dissolved layer. According to the results of the X-ray phase analysis, the partially dissolve layer consists of the WC phase. Neither cobalt nor tungsten is detected in it. These data are supported by the results of the X-ray spectral microanalysis. The weight fraction of tungsten in the partially dissolved layer is lower than that in the reference tungsten specimen and is equal to $91.3 \%$ to
$93.8 \%$, which corresponds to its weight fraction in the carbide.

To validate the suggested dissolution mechanism, the WC-Co (6\%) bars were anodically dissolved at the different values of potential corresponding to the zones I and II in the polarization curve and the dissolution duration. Table 1 summarizes the results of analyzing the produced solutions. As the potential rises, the dissolution rate of the cobalt and tungsten and the weight proportion of $\mathrm{Co}$ and $\mathrm{W}$ in the total weight fraction of the dissolved metals increase. At potentials more positive than $0.70 \mathrm{~V}$, the evolution of gas at the anode surface is observed. The results of its chromatographic analysis identified it as carbon dioxide.

Analysis of the solutions resulting from the anodic dissolution of the alloys (Table 1) and the results of the metallographic, X-ray phase, and micro-X-ray spectral analyses show that zone I of the polarization curve corresponds to the selective dissolution of the Co-W phase, which leaves W-C grains in the bar.

In this case, the dissolution process can be described by Eqs. (1) and (2):

$$
\begin{gathered}
C o \rightarrow \mathrm{Co}^{2+}+2 e\left(E^{\circ} \approx-0.59 \mathrm{~V}\right), \\
W+4 \mathrm{H}_{2} \mathrm{O} \rightarrow W \mathrm{O}_{4}^{2-}+8 \mathrm{H}^{+}+ \\
6 e\left(E^{\circ} \approx-0.12 \mathrm{~V}\right)
\end{gathered}
$$

According to the data listed in Table 1, the weight fraction of tungsten in the total weight of the dissolved metals is $11.3 \%$ to $14.2 \%$, which corresponds to the data on its dissolution in cobalt [23].

It should also be noted that the main part of the anode current is spent for the cobalt dissolution. That is why the polarization curves for the WC-Co $(6 \%)$ and cobalt electrodes are much alike in shape and close in value (Fig. 1, curves 1 and 3).

The simultaneous dissolution of the cobalt and tungsten is noticeably accelerated as the potential increases. When the potential reaches a value of $-0.02 \mathrm{~V}$, the electric current density sharply decreases to a value equal to $15 \%$ to $20 \%$ of its maximum value. 
Table 1 Dissolution rate of cobalt and tungsten as a function of the potential of the WC-Co (6\%) electrode for the $1.25 \mathrm{M}$ $\mathrm{H}_{3} \mathrm{PO}_{4}$ solution at a temperature of $18^{\circ} \mathrm{C}$.

\begin{tabular}{lcccc}
\hline Electrode potential $(\mathrm{V})$ & \multicolumn{3}{c}{ Experiment duration $(\mathrm{h})$} & \multicolumn{2}{c}{\begin{tabular}{c} 
Tissolution rate $\left(\mathrm{g} /\left(\mathrm{m}^{2} \cdot \mathrm{h}\right)\right)$ \\
fungsten weight \\
\cline { 3 - 5 }
\end{tabular}} & Cobalt & $*$ & Tungsten & - \\
\hline-0.33 & 30 & 0.095 & $*$ & - \\
-0.25 & 20 & 3.419 & 1.391 & 11.3 \\
-0.20 & 20 & 10.652 & 2.876 & 12.6 \\
-0.15 & 20 & 18.006 & 4.571 & 14.1 \\
-0.10 & 10 & 25.556 & 5.319 & 14.2 \\
-0.05 & 10 & 28.373 & 48.315 & 87.9 \\
0.80 & 5 & 16.625 & \\
\hline
\end{tabular}

* It is lower than the resolution limit of atomic absorption spectroscopy for tungsten analysis.
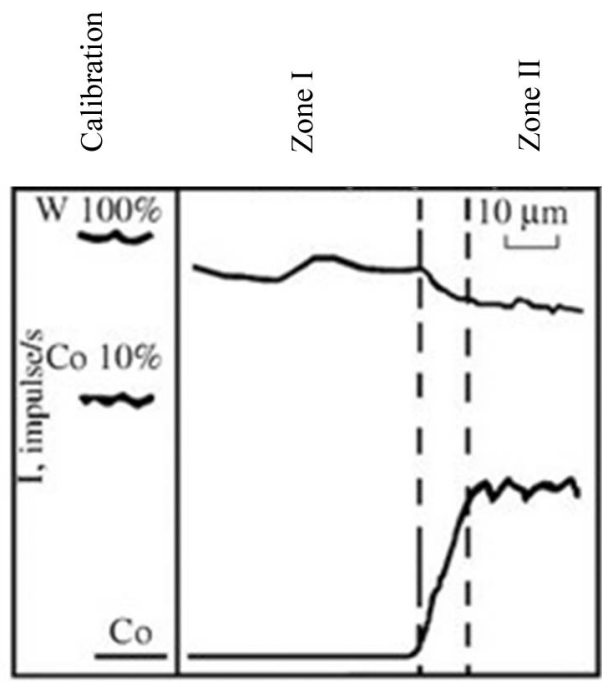

Fig. 3 Cobalt and tungsten concentration profiles for the WC-Co (6\%) alloy specimen microcrosssection after anodic dissolution in the $1.25 \mathrm{M} \mathrm{H}_{3} \mathrm{PO}_{4}$ solution at $-0.10 \mathrm{~V}$ during 10 h (calibration: signal levels for different alloy compositions; zone I: alloy subjected to dissolution and zone II: unchanged substrate (magnification $\times 600$ ).

According to the data of X-ray phase analysis, the passivated film consists mainly of tungsten oxide $\mathrm{WO}_{3}$ and cobalt phosphate. As the potential rises further, the electric current density begins to slowly increase and then sharply jumps as soon as the potential reaches $0.7 \mathrm{~V}$. This is attributed to a considerably increased contribution of the reaction into the process at the anode at potentials that are more positive than the reaction reversible potential.

$$
\mathrm{WC}+6 \mathrm{H}_{2} \mathrm{O} \rightarrow \mathrm{WO}_{4}^{2-}+\mathrm{CO}_{2}+12 \mathrm{H}^{+}+4 e
$$

In this case, almost all dissolved tungsten except for the small amount that resulted from Eq. (2) and was calculated using the cobalt dissolution data is formed as a result of Eq. (3). This is supported by the data on the contributions of separate simultaneous anode reactions into the total process at the anode.

When oxygen is absent in the solution, the cathode current corresponds to the reduction of hydrogen ions (Fig. 1, curve 4). The extrapolation of the corresponding polarization curve to the potential axis $\left(E_{c o r}\right)$ corresponds to electric currents of the same order as those measured for cobalt dissolution without polarization.

It can also be assumed that the rate of dissolution of the Co-W phase from the hard alloys depends on the thickness of the sample, the cobalt weight fraction in the alloy, and the sizes of cobalt and tungsten carbide grains. Indeed, the replacement of WC-Co (6\%) alloy particles of size $1.0 \mu \mathrm{m}$ to $2.0 \mu \mathrm{m}$ by WC-Co $(5 \%)$ particles of size $0.5 \mu \mathrm{m}$ to $1.0 \mu \mathrm{m}$ leads to 1.1 times to 1.3 times higher dissolution rates.

The selective dissolution of the WC-Co phase can be used for the recycling of hard alloy scrap. In this case, it is desirable that the separation of cobalt from carbide is accomplished at as low power consumption as possible. After the WC-Co phase is dissolved, the residual tungsten carbide after grinding can be again suitable for the production of hard-alloy tools.

\subsection{Extraction of Tungsten from Tungsten Concentrates in Ionic Melts}

Optimal compositions of the alloy that provide the 
maximum efficiency of extracting tungsten (in the form of $\mathrm{WO}_{3}$ ) from the halide-tungstate phase and its separation from iron and manganese oxides were found experimentally. The concentrations of $\mathrm{NaCl}$, $\mathrm{Na}_{2} \mathrm{SiO}_{3}$, and ( $\left.\mathrm{Fe}, \mathrm{Mn}\right) \mathrm{WO}_{4}$ for the separation of two immiscible liquids were chosen according to the recommendations [24]. Figs. $4 \mathrm{a}$ and $4 \mathrm{~b}$ illustrate the influence of the concentrations of sodium chloride in the range of $35 \mathrm{wt} \%$ to $60 \mathrm{wt} \%$ and sodium metasilicate in the range of $10 \mathrm{wt} \%$ to $40 \mathrm{wt} \%$. An extraction efficiency as high as $99 \%$ and the highest separation ratios were obtained for the melt containing (wt\%): $45 \mathrm{NaCl}, 20 \mathrm{Na}_{2} \mathrm{SiO}_{3}$ and 35 (Fe, Mn) $\mathrm{WO}_{4}$. The chemical composition of the phases and the distribution of the major components between them after high-temperature selective extraction are listed in Table 2.

Taking into account the molar ratio of components in the charge, the reaction for high-temperature selective extraction can be written as Eq. (4)

$$
\begin{gathered}
(\mathrm{Fe}, \mathrm{Mn}) \mathrm{WO}_{4}+\mathrm{Na}_{2} \mathrm{SiO}_{3} \rightarrow \mathrm{Na}_{2} \mathrm{WO}_{4} \\
+(\mathrm{Fe}, \mathrm{Mn}) \mathrm{SiO}_{3}
\end{gathered}
$$

The high technological effectiveness of

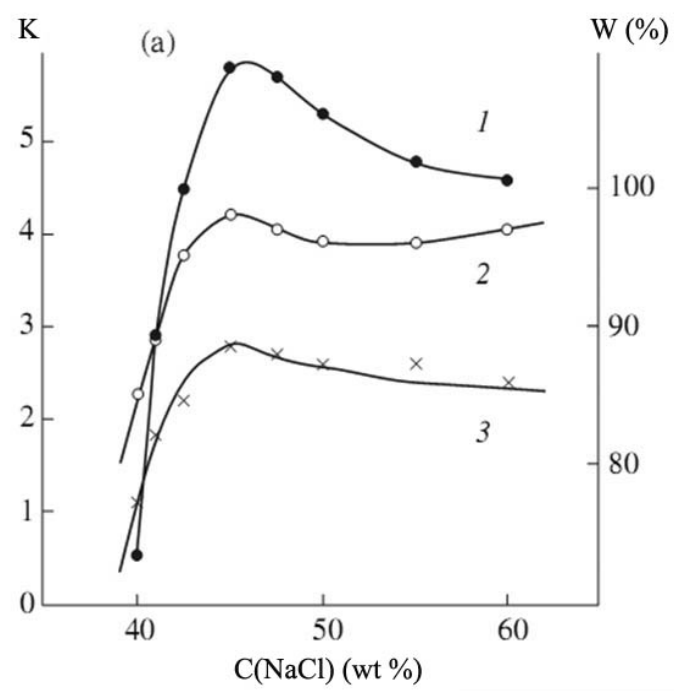

(a) high-temperature selective extraction may be attributed to the capability of sodium tungstate to mix with sodium chloride in any proportions and the immiscibility of the silicate phase having a melting point lower than $1,000{ }^{\circ} \mathrm{C}$ with the halide-tungstate phase [25].

The most effective method of processing scheelite concentrates is the high-temperature selective extraction of its mixture with wolframite in the proportion from 1:4 to $2: 1$. The use of these mixtures makes it possible to effect the process of high-temperature selective extraction without introduction of fluxes (usually used in the form of alkaline-earth metals and aluminium oxide, which is necessary for the processing of scheelite). The use of the mixture composed in the indicated proportions makes it possible to extract more than $96 \%$ of $\mathrm{WO}_{3}$ into the halide-tungstate phase. The content of calcium, iron, and manganese oxides in the latter was less than $2.5 \mathrm{wt} \%$. The halide-tungstate phase for the combined concentrates contained ( $\mathrm{wt} \%$ ): $\mathrm{WO}_{3}, 29-32$; $\mathrm{CaO}, \quad 0.03-0.12 ; \quad \mathrm{Fe}_{2} \mathrm{O}_{3}, \quad 0.02-0.05$ and $\mathrm{MnO}_{2}$, 0.01-0.04.

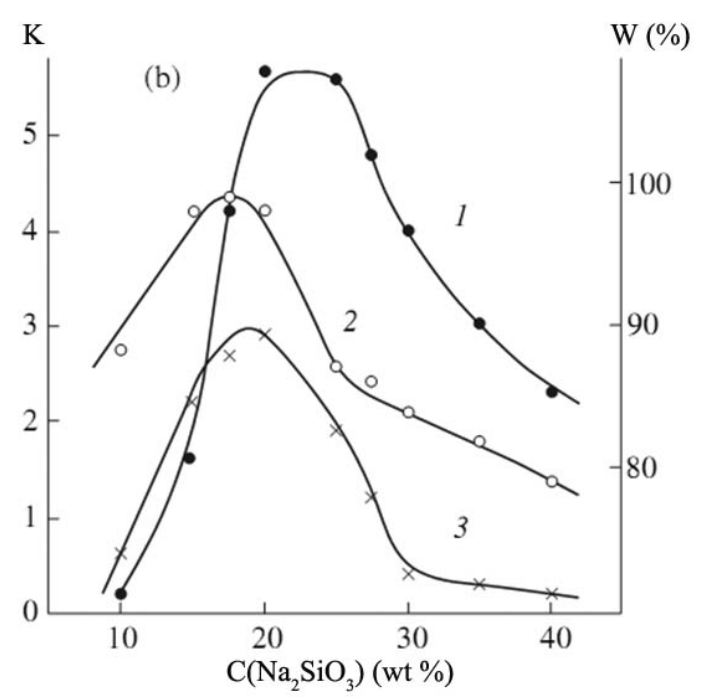

(b)

Fig. 4 Effect of the concentrations of (a) $\mathrm{NaCl}$, (b) $\mathrm{Na}_{2} \mathrm{SiO}_{3}$ on $(1,2)$ separation ratio $\mathrm{K}$ and (3) efficiency $\mathrm{W}$ of $\mathrm{WO}_{3}$ extraction into the halide phase. 
Table 2 Chemical compositions of phases and the distribution of major components between them.

\begin{tabular}{|c|c|c|c|}
\hline \multirow{2}{*}{ Phase } & \multicolumn{3}{|c|}{ Component (wt \%) } \\
\hline & $\mathrm{WO}_{3}$ & $\mathrm{FeO}$ & $\mathrm{MnO}$ \\
\hline & \multicolumn{3}{|c|}{ Chemical composition } \\
\hline Halide & 31.20 & 0.21 & 0.33 \\
\hline \multirow[t]{2}{*}{ Silicate } & 0.35 & 10.31 & 27.70 \\
\hline & \multicolumn{3}{|c|}{ Distribution } \\
\hline Halide & 99.61 & 7.32 & 3.65 \\
\hline Silicate & 0.39 & 92.68 & 96.35 \\
\hline
\end{tabular}

\section{Conclusions}

The potentiostatic mode of anodic dissolution of tungsten carbide-cobalt alloys in phosphoric acid solutions, which makes it possible to selectively dissolve tungsten and cobalt and separate the solid tungsten carbide phase, is experimentally validated and practically implemented.

The curves of the rate of dissolution of cobalt and tungsten in the WC-Co $(6 \%)$ alloy versus the electrode potential and dissolution duration are determined.

It shows that tungsten is extracted from tungsten ores and concentrates in sodium chloride-sodium metasilicate melts into the halide phase at $1,050{ }^{\circ} \mathrm{C}-1,100{ }^{\circ} \mathrm{C}$. The compositions of the melts that provide the extraction efficiency as high as 99\% and maximal ratios of separation of the components between the phases are chosen.

\section{References}

[1] Klyachko, L. I., and Leytman, M. S. 2005. "Tungsten Scrap: Recycling Technology and the Russian Market." Non-ferrous Metals 3: 101-104.

[2] Pivovarov, M. N., and Vlasova, A. V. 2003. "New Recycling Method for Waste Hard Alloy Lumps." New Technology 1: 89-95.

[3] Shapoval, V. I., Malyshev, V. V., and Sushinskii, N. M. "Extraction of Diamonds and Tungsten from Waste Cutting and Drilling Tools." Ecotechnologies and Resource-Saving 6: 46-52.

[4] Merkulov, V. F., Adelshin, Yu. G., and Zhdanovich, K. K. 1984. "Technology of Tungsten Recycling form Drilling Bits Wastes." Steel 10: 30-32.

[5] Gulisija, Z., Odanovic, Z., and Gulisija, R. 1995. "Investigation of a Technical Method for the Reclamation of Hard Metal Scrap." Sci. Sinter 27: 211-217.
[6] Liu, X., Xu, S., and Wang, K. 2003. "Recycling of WC-Co Alloys." Non-ferrous Metals 55: 59-61.

[7] Alkatsev, M. I., Svistunov, N. V., and Trocenko, I. G. 2008. "Regeneration of Solid WC-Co Alloy with Gaseous Zinc." Non-ferrous Metallurgy 3: 17-21.

[8] Chyzhykov, D., Trusova, V., and Hazan, A. 1976. A Method of Rare Refractory Metal Recycling by Oxidation. USSR Patent 528,341, filed November 27, 1974, and issued September 15, 1976.

[9] Zarubitsky, O. G., Orel, V. P., and Dmitruk, B. F. 2004. "Pyrochemical Technology of Tungsten and Cobalt-Containing Raw Materials." Journal of Applied Chemistry 77: 1761-1763.

[10] Nikolaev, A. I., Mayorov, V. G., and Kopkov, V. K. 2003. "Low-Waste Technology of Carbide Materials Processing to Give Compounds of Cobalt and Tungsten." In Resource-Reproducing, Low-Waste and Environmentally Friendly Technologies of Natural Resources Development, 148-149.

[11] Belov, A. 2002. The Method of Extraction and Separation of Tungsten and Cobalt Compounds. RU Patent 2,190,678, filed October 5, 2001, and issued October 10, 2002.

[12] Guzeyeva, T. I., Levshanov, A. S., and Makarov, F. V. 2005. "Thermodynamics of Fluorination of Hard Alloys Based on Tungsten Carbide by Fluorine." In Proceedings of the Tomsk Polytechnical University, 90-92.

[13] Edtmaier, C., Schiesser, R., and Meissl, C. 2005. "Selective Removal of the Cobalt Binder in WC-Co Based Hardmetal Scraps by Acetic Acid Leaching." Hydrometallurgy 76: 63-71.

[14] Angerer, T., Luidold, S., and Antrekowitsch, H. 2011. "Technologien Zum Recycling Von Hartmetallschrotten, Tell. 3." Erzmetall 64: 328-336.

[15] Kim, S., Seo, B., and Son, S. H. 2014. "Dissolution Behavior of Cobalt from WC-Co hard Metal Scraps by Oxidation and Wet Milling Process." Hydrometallurgy 143: $28-33$

[16] Ishida, T., Itakura, T., Morigushi, H., and Ikegava, A. 2012. "Development of Technologies for Recycling Cemented Carbide Scrap and Reducing Tungsten Use in Cemented Carbide Tools." Sei. Technical Review 75: 
$38-46$.

[17] Stopic, S., Gurmen, S., and Friedrich, B. 2004. "Recovery of Cobalt Powder and Tungsten Carbide from Cemented Carbide Scrap-Part I: Kinetics of Cobalt Acid Leaching." Erzmetall World of Metallurgy 57: 143-147.

[18] Stopic, S., Gurmen, S., and Friedrich, B. 2004. "Recovery of Cobalt Powder and Tungsten Carbide from Cemented Carbide Scrap-Part II: Recovery of Submicron Cobalt Powder from the Leach Solution." Erzmetall World of Metallurgy 57: 341-346.

[19] Chayka, T. V., Derbasova, N. M., and Gavrish, V. M. 2013. "Studies of Separation of Tungsten Carbide and Cobalt by Microbial Destruction of Tungsten and Cobalt Containing Wastes." In Proceedings of the National Technical, 125-132.

[20] Sadoway, D. R. 1995. "New Opportunities for Metals Extraction and Waste Treatment by Electrochemical
Processing in Molten Salts." Journal of Materials Research 10: 487-492.

[21] Baibatyrov, E. N., Palanker, V. Sh., and Sokol'skii, D. V. 1974. "Electrochemical Evolvement of Hydrogen on Tungsten Carbide." Electrochemistry 10: 162-165.

[22] Dasoyan, Ya, M., Pal'mskaya, Ya, I., and Sakharova, E. V. 1989. Technology of Electrochemical Coatings. Leningrad: Mashinostroenie.

[23] Okamoto, H. 2000. Desk Handbook: Phase Diagrams for Binary Alloys, 2nd Ed.. Materials Park, Ohio, USA: ASM International.

[24] Gomes, J. M. 1985. "New Method of Tungsten Carbide Manufacturing." International Journal of Refractory and Hard Metals 4: 177-178.

[25] Makhosoev, M. V., Alekseev, F. P., and Lutsyk, V. I. 1978. State Diagrams of Molybdenum and Tungsten Systems. Novosibirsk: Nauka. 